\title{
A Responsabilidade de Traduzir o In-traduzível: Jacques Derrida e o Desejo de [la] Tradução*
}

\author{
(The Responsibility of Translating the Un-translatable: \\ Jacques Derrida and the Desire for $[l a]$ Translation)
}

\author{
Paulo OTtoni \\ (Unicamp/2001)
}

\begin{abstract}
1. Não falei de intraduzibilidade ou de idiomaticidade absolutas, mas de uma maior economia (tratava-se para mim de dizer em poucas palavras francesas, neste caso, nessa ocorrência, o que se pode traduzir, de todo jeito, em toda língua, com menos gastos); o que basta para mudar o sentido político [itálico de Derrida] deste gesto.

2. Acredito que a afirmação irredutível e necessária de uma certa idiomaticidade, e de uma certa unicidade, como de uma certa unidade diferante [différante], isto é, impura - e eu queria demonstrá-lo na prática. O que fazemos em seguida, com esta afirmação e com esta impureza, é a própria política [itálico meu].

3. digamos, enfim, que quis usar, outro gesto político [itálico meu], de meu próprio direito à ironia e, expondo-me assim na minha língua, dar um exemplo desta necessidade fatal, assim como de seus riscos.
\end{abstract}

Jacques Derrida Mal de Arquivo **

\footnotetext{
* Uma versão preliminar deste texto com o título As línguas da tradução e a responsabilidade do traduzir: Jacques Derrida e o desejo de [la] tradução foi apresentada como comunicação na mesaredonda: Discurso e responsabilidade em tradução no VIII Encontro Nacional de Tradutores e II Encontro Internacional de Tradutores, promovido pela ABRAPT - Associação Brasileira de Pesquisadores em Tradução e pelo Departamento de Letras Anglo-Germânicas e Programa de Pós-graduação em Estudos Lingüísticos da Faculdade de Letras da Universidade Federal de Minas Gerais, no dia 24 de julho de 2001. Este trabalho faz parte de uma pesquisa financiada parcialmente pelo CNPq, processo 300705/98-0, e do Projeto: TRADUZIR DERRIDA - Políticas e Desconstruções.

** Esta epígrafe é a resposta de Jacques Derrida a Geoffrey Bennington, no final da conferência: O conceito de arquivo - Uma impressão freudiana proferida em 5 de junho de 1994, em Londres. Retomarei e discutirei estes três pontos relacionados à questão da intraduzibilidade na parte final deste trabalho.
}

D.E.L.T.A., 19:EsPECIAL, 2003 (163-174) 
ABSTRACT: How should one consider the responsibility of the translator, who is located "between" the differences of two linguistic systems and "in the middle" of the various idioms constitute each of the languages involved in the translation? (P. Ottoni). What is the role of the translator in inter-acting with both his/her mother tongue and the idiom of the other? These two questions will be discussed in order to reflect on the responsibility of translating the un-translatable. Two hypotheses orient the paper: 1 an idiom spoken idiomatically is known as the mother tongue and is not appropriated, so that accommodating the other in one's own language automatically considers his/her idiom (J. Derrida) and 2 - face-to-face with language and its idioms, the translator is trapped in a double (responsibility) bind; faced with sometbing which cannot be translated, he/she is forced to perceive it in another way. In conclusion, how should one consider the responsibility of translating the un-translatable Jacques Derrida?

KEY-WORDs: Responsibility; Un-translatable; Deconstructions; Derrida.

RESUMO: Como pensar a responsabilidade do tradutorla que se encontra "entre" a diferença de dois sistemas lingüisticos e no "meio" das várias línguas que compõem as linguas envolvidas na tradução? (P. Ottoni). Qual o papel do tradutor ao ter que (con) viver com sua língua materna e o idioma do outro? Procurarei discutir estas duas questões para pensar a responsabilidade de traduzir o in-traduzível. Parto de duas hipóteses: 1-falar idiomaticamente seu idioma é o que se chama língua materna, o que não se apropria; e, acolher o outro na sua língua é levar em conta naturalmente seu idioma (J. Derrida); 2 - O tradutor, neste corpo-a-corpo com a língua e o idiomático, está preso numa dupla responsabilidade na operação de tradução: frente ao in-traduzível do idioma, e tendo que apreender de outro modo esta intraduzibilidade. Em resumo, como refletir sobre a responsabilidade de traduzir o in-traduzivel Jacques Derrida?

PalavRas-CHave: Responsabilidade; In-traduzivel; Desconstruçôes; Derrida.

Frente à questão do in-traduzível qual a responsabilidade do traduzir?

Como acolher o outro na minha língua, no meu idioma? A quem, e a o quê se deve ser responsável? Não seria a responsabilidade do traduzir a responsável pela doação da língua e do idioma para o outro? Qual a responsabilidade de um tradutor que se encontra "entre" a diferença de dois sistemas lingüísticos e no "meio" das várias línguas, dos vários idiomas, que compõem as línguas envolvidas na tradução? (cf. Ottoni 1997: 23-4). Como (con)viver com o in-traduzível e a tradução, e com a diferença "entre" língua e idioma num mesmo sistema lingüístico? 
Marcos Siscar (2000: 68-9), sobre a responsabilidade do leitor e do tradutor de Jacques Derrida afirma:

Se ao leitor dos textos de Derrida cabe assumir a responsabilidade de sua leitura, não lhe é menos necessária a consideração da singularidade irredutível do texto que traduz, isto é, a consideração de seu caráter intraduzível. Desse caráter intraduzível depende, na verdade, a própria noção de responsabilidade. [...] A responsabilidade teria algo também de resposta, de atenção, ao chamado de um outro. Ela pode ser entendida como momento ético da tradução, como momento crítico no sentido de crise da escolha, assunto de fato pouco sublinhado e que tem conseqüências reais na prática da tradução.

Quero ressaltar nessa afirmação o aparecimento da questão da política a partir do seu questionamento de como traduzir o intraduzível, e por que traduzir o intraduzível. Ao comentar o modo como relaciona a noção de responsabilidade ao intraduzível, Siscar afirma:

A questão "como traduzir o intraduzível?" se liga assim à questão "por que traduzir o intraduzível?”, implicando uma problemática que é tão lingüística quanto filosófica, tão política [itálico meu] quanto psicanalítica. Como e por que traduzir Jacques Derrida, o intraduzível? É essa responsabilidade da tradução diante da hospitalidade ou da violência de seu gesto que deveria, portanto, ser alçada à condição de questão para o tradutor.

Segundo Derrida (1998: 261) a questão do in-traduzível e da sua responsabilidade tem ligações estreitas com a questão da língua materna. Ele afirma: "falar idiomaticamente seu idioma é o que se chama de língua materna, o de que não se apropria, e acolher o outro na sua língua é levar em conta naturalmente seu idioma”. O tradutor - neste corpo-a-corpo com a língua e o idiomático - está preso numa dupla fidelidade no trabalho de traduzibilidade: "frente ao in-traduzível do idioma, e tendo que apreender de outro modo esta intraduzibilidade" (Derrida,1998: 224). Minha primeira hipótese é a de que, ao refletir sobre a dupla fidelidade do tradutor na (re)conciliação do intraduzível e da tradução, Derrida deixa uma espécie de brecha na qual possa emergir a questão da responsabilidade que, por um lado, pode ser um outro nome para a fidelidade, e por outro, ao propor essa dupla fidelidade, que entram em confronto, está querendo dizer que não há fronteiras entre língua e idioma. Assim como pensar a contaminação entre a língua (enquanto um sistema lingüístico) e o idiomático? Entre o in-traduzível e a tradução? 
Uma das características mais importantes dos textos de Derrida é o papel que exercem a tradução e os tradutores no seu pensamento. Numa entrevista concedida a France Culture, Derrida (cf.1999a: 56) afirmava que "é com os tradutores de todos os países que me entendo melhor, que trabalho melhor". Num outro momento, ele se pergunta como os tradutores agiriam ao traduzir os sintagmas idiomáticos - figuras ou fórmulas específicas do francês, na sua essência im-possíveis de serem traduzidos no interior de toda operação de tradução? (cf. Derrida 2000 a: 249 - 50)

As relações entre desconstrução e tradução já estão presentes, de uma maneira indissociável, desde a tradução por Derrida de L'origine de la géométrie de Husserl ${ }^{1}$. Nessa publicação de 1962 na sua Introduction, já podemos perceber a questão da responsabilidade e o papel do tradutor e do pensador sobre a fenomenologia de Husserl. A tradução, o traduzir e o tradutor Derrida ao longo desses quarenta anos de reflexão tomam formas diferentes: as modificações se dão na maneira como ele - tradutor - se envolve com a tradução e como é envolvido, por ela, ao traduzir. Cada vez mais a experiência da tradução faz parte do pensamento derridiano.

Nos últimos anos, Derrida tem colocado a possibilidade de se dizer "desconstruções" no plural. Minha segunda hipótese é a de que, ao enunciar este "plural", além de deixar em suspenso a identificação direta entre ele e "a" desconstrução, está assumindo, de certa maneira, a tradução como um desejo que cada vez mais se evidencia e se explicita em sua argumentação, colocando implícita e explicitamente a responsabilidade do traduzir como um dos fatores que entram em jogo ao responsabilizar o papel do tradutor/leitor como coadjuvante na disseminação dos seus textos.

É a partir da possibilidade dessas "desconstruções” que intensifica gradualmente nas suas reflexões, não só uma dificuldade cada vez maior, mas também cada vez mais complexa, de distinguir tradução, traduzir e tradutor/a. Essa não-distinção passa a ter um papel relevante e decisivo para mostrar como a contaminação entre as línguas envolvidas na tradução revela seus aspectos idiomáticos, proporcionando, então, uma outra maneira de distinguir as línguas, os idiomas e as nacionalidades no texto derridiano. A responsabilidade do traduzir passa, então, a ter um papel fundamental frente a este caráter in-traduzível desses textos e como o

1 Não há tradução para o português. 
próprio Derrida assume a sua responsabilidade juntamente com a de seus tradutores.

Vejamos em três trabalhos recentes como a relação tradução, traduzir e tradutor/a participam de maneira decisiva no pensamento de Derrida. Em Le toucher, Jean-Luc Nancy ${ }^{2}$, ele questiona a im-possibilidade da tradução de uma frase analisada por Nancy: La pensée pèse exactement le poids du sens $^{3}$, e chama a atenção para a afinidade entre penser e peser na tradução dessa frase para o alemão e o inglês. Para ele a questão do idiomático está associada ao in-traduzível numa outra língua. Como considerar, então, pergunta Derrida, numa tradução, a ínfima diferença, nesse caso, da letra n? (cf. Derrida, 2000a: 89). Na tradução dessa frase para o português, o nosso idioma revela sua singularidade: $O$ pensar pesa exatamente o peso do sentido. Não só associamos pensar e pesar, como penser e peser em francês, como também temos a relação sonora e semântica entre pesa e peso, e, talvez possamos associar, também, essa aliteração às questões do gênero, a partir da proximidade e da diferenciação entre as letras $a$ e 0 . Derrida, nesta mesma direção, questiona a im-possibilidade de se traduzir a afinidade entre denken e danken do alemão e thinking e thanking do inglês, afinidades inscritas no corpo da língua, na simples troca de um $e$ ou um $i$, por um a. Como um tradutor, questiona Derrida, agiria ao traduzir esses sintagmas idiomáticos, na sua essência im-possíveis no interior da operação de toda tradução? (cf. Derrida, 2000a: 249-50). Ao levantar esta questão Derrida não pede mais ao tradutor/a fidelidade ao seu texto, mas questiona a sua responsabilidade frente ao seu texto, frente ao in-traduzível do idioma. Não há mais fidelidade nas desconstruções, há responsabilidades.

Esse mesmo argumento está colocado de maneira diferente no postscriptum do Estados-da-alma da psicanálise, o impossível para além da soberana crueldade (Derrida 2001a). Depois de fazer um comentário sobre as figuras idiomáticas que envolvem as palavras avoir, faire, vouloir e mal presentes em toda a argumentação da questão psicanalítica, Derrida se preocupa com os sofrimentos do tradutor/a que gostariam de respeitar, em suas traduções, cada uma dessas palavras singulares do idioma francês. Como her-

2 Não há tradução para o português.

3 Analiso também esta frase no texto Traduction et déconstruction: la contamination constitutive et nécessaire des langues. Publicado nas Actas del Congresso - Últimas Corrientes Teóricas en los Estudios de Traducción y sus Aplicaciones, Salamanca - Espanha, registrado em CD-ROM, 2001, pp. 537 - 41. 
deiro da língua francesa, questiona se tem culpa nessa suposta impossibilidade de traduzir, e nessa impossibilidade de uma tradução econômica palavra por palavra. Por um lado, responde não ter culpa, essa impossibilidade faz parte da língua, ele a herdou; por outro tem culpa, e essa herança faz com que ele traia a sua verdade. Conclui o livro perguntando: o álibi ainda é inevitável? Não seria muito tarde? (cf. Derrida, 2001a: 93). De maneira inusitada, o tradutor Antonio Romane Nogueira e a tradutora Isabel Kahn Marin, para o português, entram no jogo da tradução/desconstrução e, numa nota aos leitores, comentam: "herdeiros da língua portuguesa, os tradutores acreditam ter traduzido Derrida. Sem álibi”“4 (Derrida, 2001a: 93).

No colóquio sobre Hélène Cixous ${ }^{5}$, Derrida ao comentar a obra de Cixous, e relacioná-la à quase intraduzibilidade, mas intraduzível e inconfessável também pelo esboço ininterrupto de um parricídio - que, segundo ele, é uma tese sobre a tradução -, propõe a elipse de um silogismo dogmático composto de três pontos: "1. o quase parricídio é a condição da tradução; 2. a tradução traduz sempre e somente o intraduzível; 2. e o quase parricídio permanece a condição da tradução do intraduzível" (cf. Derrida, 2000b: 17). Essa tese sobre tradução que perpassa toda a reflexão que faz de e para Cixous deve também servir aqui como uma espécie de estratégia para nossa reflexão sobre a responsabilidade frente ao intraduzível. Quero lembrar que para Derrida não há uma oposição nos moldes clássicos entre o traduzível e o intraduzível. Nesses três trabalhos, podemos considerar essa aparente oposição como uma espécie de fortalecimento de uma outra lógica, a própria mise-en-scène do double bind.

Quando publica a Voz e o Fenômeno, Derrida (1967) ao comentar as morfologias puras das Bedeutungen na introdução, não traduz a palavra bedeuten. Logo no primeiro capítulo ele dá uma explicação para a sua tradução que se diferencia da tradicional já existente em francês. Uma vez que sua opção de tradução de bedeuten por vouloir-dire [querer-dizer] fará parte integrante de sua argumentação. Esse tipo de responsabilidade do traduzir

\footnotetext{
4 Na resenha Arquivos Secretos - Três obras do filósofo francês Jacques Derrida discutem os limites da tradução (Mal de Arquivo, Três Tempos sobre a História da Loucura e Estados-da-alma da Psicanálise), publicada no caderno Mais! número 493 - Jornal Folha de São Paulo - 22/julho/2001 - p. 22-3. Nessa resenha discuto a postura dos tradutores e tradutoras destes três livros.

5 O livro Hélène Cixous - croisées d'une oeuvre, edição Galilée, 2000, (inédito em português) é a reunião dos trabalhos apresentados no colóquio consagrado a Cixous, realizado de 22 a 30 de junho de 1998 em Cerisy-la-Salle, França.
} 
pode não ser exclusividade da escrita derridiana, mas, no decorrer da desconstrução, neste caso, da fenomenologia de Husserl, percebemos como a particularidade desta operação de tradução vai participar de modo efetivo na sua argumentação. A experiência da tradução nos primeiros textos, a Voz e o Fenômeno e a Introduction de L'origine de la géométrie de Husserl, é importante porque, de maneira muito peculiar, ela vai lentamente emergindo e contaminando seu pensamento ao longo desses quarenta anos. Dividirei hipoteticamente esses quarenta anos em duas partes. A primeira compreende desde a publicação da sua tradução de Husserl em 1962 até a publicação de Survivre/Journal de bord, em 1986, que foi publicado primeiramente na sua versão traduzida, por James Hulbert, para o inglês - Living On/Border Lines -, em 1979. Derrida trata das implicações e dos envolvimentos das questões da tradução e do papel do tradutor na crítica literária americana. Derrida assume, também, o papel de tradutor de seu próprio texto, ocupando o espaço tradicionalmente reservado às notas do tradutor no final - na borda - de cada página ao longo de todo o texto. Este é o momento em que a desconstrução já está, diferentemente dos textos iniciais, de certo modo, dialogando, nesse caso específico, com os desconstrutivistas americanos e seus tradutores e o que, cada vez mais, está presente na maneira como Derrida relaciona as línguas, os idiomas e as nacionalidades. A partir daí se inicia a segunda parte, que chega até esses últimos textos comentados acima. Entre a primeira e a segunda partes não há fronteiras, há contaminação e o fortalecimento da relação traduçãodesconstrução trará conseqüências para o texto derridiano e assim, a responsabilidade de traduzir o in-traduzível passa a ter uma importância fundamental na composição desses textos.

Numa entrevista concedida a Carmen Gonzáles-Marín, em 1986, Derrida respondendo à pergunta: o senhor acredita que seus textos traduzidos dizem o mesmo que os textos franceses?, afirma: os textos traduzidos nunca dizem as mesmas coisas que os textos originais, sempre ocorre algo de novo; o paradoxo da tradução é o fato de que um texto traduzido chega a outra coisa, mas outra coisa que está em relação consigo mesma (cf. Derrida, 1999b: 62). No final da entrevista, comenta que sempre escreve pensando na tradução, e que entre a desconstrução e a experiência da tradução existe uma afinidade essencial. Se assumimos, hipoteticamente, esta divisão em duas partes, essa entrevista, e o texto Survivre/Journal de bord/ Living On/Border Lines podem servir como uma espécie de fronteira onde não há lugar para fronteiras. 
No encontro de Rabat no Morrocos ${ }^{6}$, Derrida inicia seus comentários afirmando que "descontruções" deveria se dizer no "plural" (como coloquei acima), criando com esse "plural" uma estreita relação entre o idioma, que segundo ele não se confunde com a língua, e os enigmas da tradução. Ora, que "plural" é esse que não se diferencia de um singular? Segundo Derrida, se tivesse que arriscar uma definição de desconstrução, diria simplesmente "mais de uma língua" (cf. Derrida, 1998: 221). A desconstrução, segundo ele, não é intraduzível, mas ligada à questão do intraduzível. Para Petrosino (1994: 127), um dos comentaristas mais brilhantes da desconstrução, "a pureza é impossível no pensamento de Derrida, porque a contaminação é necessária”. Dessa afirmação pode-se inferir também a necessidade e impossibilidade da tradução, e assim considerar a contaminação e a tradução como necessárias e impossíveis para Derrida. É nessa outra lógica, na qual necessidade e impossibilidade estão em pé de igualdade, que podemos, em concordância com Derrida, afirmar que há "desconstruções", e que esse "plural" é uma maneira de fortalecer e ampliar, cada vez mais, a responsabilidade de traduzir o in-traduzível.

Vejamos os três pontos levantados por Derrida na epígrafe deste texto, destacando que em cada um deles a questão do político e da política deflagram de modo diferente a questão da responsabilidade. Esses três pontos resumem a resposta de Derrida a um comentário de Geoffrey Bennington a partir da seguinte afirmação de Derrida: "L'Un se garde de l'autre pour se faire violence (parce qu'il se fait violence et un vue de se faire violence). Cela ne peut se dire et donc s'archiver de façon aussi économinique qu'un français ${ }^{7}$ [cf. p. 125 ed.fr.]. Derrida comenta em nota:

No final desta conferência, não sem ironia, com tanta profundeza quanto espanto, mas, como sempre, com uma intratável lucidez, Geoffrey Bennington observou que, ao sublinhar e portanto pôr em prática uma tal intraduzibilidade, eu me arriscava a repetir o gesto que parecia estar pondo em questão no outro, isto é, a afirmação do único ou do idioma.

\footnotetext{
6 O Encontro de Rabat com Jacques Derrida foi realizado em junho de 1996 e as comunicações e os comentários de Derrida foram publicados no número 13 dos Cahiers Intersignes (Paris) e pelas Éditions Toubkal (Casablanca), em 1998.

7 Um se guarda do outro para se fazer violência (porque se faz violência e com vistas a se fazer violência). Isto não se pode dizer e, portanto, arquivar de maneira tão econômica senão em francês (Tradução para o português de Claudia de Moraes Rego, cf. p. 100).
} 
Em seguida resume os três pontos fundamentais da sua resposta:

1. Não falei de intraduzibilidade ou de idiomaticidade absolutas, mas de uma maior economia (tratava-se para mim de dizer em poucas palavras francesas, neste caso, nessa ocorrência, o que se pode traduzir, de todo jeito, em toda língua, com menos gastos); o que basta para mudar o sentido político [itálico de Derrida] deste gesto.

Derrida faz uma diferença entre a intraduzibilidade e a idiomaticidade absolutas e a economia da língua francês, o que vai trazer a questão da responsabilidade - o sentido político - do traduzir frente ao in-traduzível. Ele continua:

2. Acredito que a afirmação irredutível e necessária de uma certa idiomaticidade, e de uma certa unicidade, como de uma certa unidade diferante [différante], isto é, impura - e eu queria demonstrá-lo na prática. O que fazemos em seguida, com esta afirmação e com esta impureza, é a própria política [itálico meu].

O fato de assinalar para uma certa idiomaticidade impura, que ele a faz na sua própria prática, é a sua própria política, e conclui:

3. Digamos, enfim, que quis usar, outro gesto político [itálico meu], de meu próprio direito à ironia e, expondo-me assim na minha língua, dar um exemplo desta necessidade fatal, assim como de seus riscos.

Derrida comenta que seu "gesto político" é um direito e assim se responsabiliza pelo seu próprio gesto. Propõe para si - na sua cena performativa - a responsabilidade do tradutor que se confronta com o in-traduzível e a idiomaticidade impura. Encena o "gesto político" - a responsabilidade da sua própria in-traduzibilidade. Gesto que vai ser vivido e que pertence também ao tradutor/leitor ao traduzir o idiomático derridiano e o idiomático Derrida.

Como pensar esta responsabilidade como gesto político, na política das traduções dos textos de Derrida, "das desconstruções” no Brasil? Podemos afirmar que há "desconstruções" no Brasil?

Derrida esteve no Brasil por duas vezes. Em dezembro de 1995, no dia 4, proferiu uma conferência no auditório do MASP, em São Paulo, 
sobre a História da Mentira ${ }^{8}$. Retornou em junho de 2001, com René Major, e nos dias 7, 8 e 9 participou, no Rio de Janeiro, de um encontro em torno das questões sobre a psicanálise. Suas duas participações foram de extrema importância para levantar a questão "das desconstruções" no Brasil $^{9}$. Leyla Perrone-Moisés (2001) faz um magnífico resumo das falas de Derrida nesses três dias, destacando as principais questões discutidas, e a importância de sua presença no Brasil.

Retomando a questão de Siscar: Como e por que traduzir Jacques Derrida, o intraduzível? Como pensar numa tradução do in-traduzível? Mas devemos também nos perguntar: Qual é a responsabilidade de se traduzir Derrida no Brasil? Como deixar que a língua e o idioma do Brasil se contaminem pelas línguas e pelos idiomas "das desconstruções"?

Numa entrevista publicada recentemente, ao comentar a obra do poeta Paul Celan, Derrida afirma que não se apropria de uma língua, nem mesmo da língua materna, mas se deve suportar o corpo-a-corpo com ela. Quando só temos uma língua materna e que está enraizada no seu lugar de nascimento, mesmo neste caso, a língua não nos pertence; o idiomático, o que é mais próprio de uma língua, não se deixa apropriar. Por mais paradoxal que pareça, o idioma é aquilo de que a língua não se apropria, e é o que resiste à tradução (cf. Derrida, 2001c: 85-6). Traduzir não seria então dar nossa língua, nosso idioma, o que não nos pertence, para o outro? Uma vez que só pode haver "desconstruções” onde há traduções, como é possível, então, traduzir Derrida a partir de Derrida, o in-traduzível? e, fazer com que ele, cada vez mais, fale nossa língua e nosso idioma?

E-mail: ottonix@hotmail.com Recebido em fevereiro de 2002

8 O texto da conferência, proferida em 4 de dezembro de 1995, História da Mentira: prolegômenos, foi traduzido por Jean Briant e publicado na revista Estudos Avançados volume 10, número 27 pela USP em 1996.

9 Quero lembrar aqui a publicação do livro Em torno de Jacques Derrida, editado pela 7Letras/ $\mathrm{CNPq}$, organizado por Evando Nascimento e Paula Glenadel; reúne os trabalhos apresentados no I Seminário de Estudos Literários e Filosóficos: Em torno de Jacques Derrida, realizado em 12 e 13 de abril de 2000 na Universidade Federal Fluminense. Em alguns dos textos, posso de algum modo sentir a preocupação, não totalmente explícita, do que pode ser a "desconstrução no Brasil". 


\section{REFERÊNCIAS BibLIOGRÁFICAS}

Derrida, Jacques. 1962. L'origine de la géométrie. PUF, Paris. .1967. La voix et la fénomène. PUF, Paris. A voz e o fenômeno, tradução para o português de Lucy Magalhães pela Jorge Zahar Editor, de 1994, Brasil. A voz e o fenómeno, tradução para o português de Maria José Semião e Carlos Aboim de Brito, pela Edições 70, em 1996, Portugal.

.1979-1986. Living On/border Lines. IN: Deconstruction E Criticism, tradução para o inglês de James Hulbert. Primeira edição publicada pela The Seabury Press, NY, em 1979 e a segunda pela Continuum, N Y em 1999. Survivre/Journal de bord. IN: Parages, Éditions Galilée, 1986, Paris.

. 1998. Fidélité à plus d'un - Mériter d'hériter où la généalogie fait défaut. IN: Rencontre de Rabat avec Jacques Derrida - Idiomes, Nationalités, Déconstructions. Cahiers Intersignes (Paris) e Éditions Toubkal (Casablanca), p. 221-26.

. 1999a. Sur Paroles - instantanés philosophiques. Éditions de l'aube, Saint-Étienne - France.

. 1999b. Lo Ilegible. IN: No escribo sin luz artificial. Cuatro, Ediciones

- Valladolid, Espanha, p. 49-64. Entrevista publicada pela primeira vez na Revista de Occidente número 62/63, 1986, p. 160-82.

. 2000a. Le toucher, Jean-Luc Nancy. Éditions Galilée, Paris.

. 2000b. H. C. pour la vie, c'est à dire... IN: Hélène Cixous - croisées d'une oeuvre. Éditions Galilée, Paris, p. 13-140.

. 2001a. Estados-da-Alma da psicanálise-O impossivel para além da soberana crueldade. Tradução para o português de Antonio Romane Nogueira e Isabel Kahn Marin. Editora Escuta Ltda, São Paulo. États d'âme de la psychanalyse - L'impossible au-delà d'une souveraine cruauté. Éditions Galilée, Paris, 2000. . 2001b. Mal de Arquivo - Uma Impressão Freudiana. Tradução de Cláudia de Moraes Rego, Relume Dumará - Rio de Janeiro. Mal d'archive - une impression freudienne, Éditions Galilée, Paris, 1995.

. 2001c. La langue n'appartient pas - Entretien avec Jacques Derrida. IN: Europe número 861/862, janeiro-fevereiro 2001, p. 81-91.

Otтоni, Paulo. 1997. Compreensão e Interpretação no Ato de Traduzir.Reflexões sobre o Enunciado e a Significação. IN: Lusorama-Zeitschrift für Lusitanistik - número 32, Berlin, p. 19-27. 
Perrone-Moisés, Leyla. 2001. Notas sobre Jacques Derrida no Rio. In: Caderno Mais! número 491 - Folha de São Paulo 8 de julho de 2001, p.12-3.

Petrosino, Silvano. 1994. Jacques Derrida et la loi du possible. Traduzido do italiano (1983) por Jacques Rolland, Éditions du Cerf, 1994, Paris.

Siscar, Marcos. 2000. Jacques Derrida, o intraduzível. IN: Alfa - Revista de Lingüiśtica v. 44 (n. esp) Tradução, desconstrução e pós-modernidade, p. 59-69. 